\title{
Simple and rapid high-performance liquid chromatography method for the determination of ofloxacin concentrations in plasma and urine
}

\author{
Chandra Immanuel* ${ }^{*}$, A.K. Hemanth Kumar \\ Tuberculosis Research Centre (Indian Council of Medical Research), Chennai 600 031, India \\ Received 7 November 2000; received in revised form 4 April 2001; accepted 14 May 2001
}

\begin{abstract}
A high-performance liquid chromatographic method for the determination of ofloxacin in human plasma and urine was developed. The method involved deproteinisation of the sample with perchloric acid and analysis of the supernatant using a reversed-phase $\mathrm{C}_{18}$ column and fluorescence detection at an excitation wavelength of $290 \mathrm{~nm}$ and an emission wavelength of $460 \mathrm{~nm}$. The assay was linear from 0.5 to $10.0 \mu \mathrm{g} / \mathrm{ml}$. The relative standard deviation of intra- and inter-day assays was lower than 5\%. The average recovery of ofloxacin from plasma was $93 \%$. The method was evaluated in samples from healthy subjects whose drug levels were already measured by microbiological assay. C) 2001 Elsevier Science B.V. All rights reserved.
\end{abstract}

Keywords: Ofloxacin

\section{Introduction}

Ofloxacin (OFX) is a fluoroquinolone antimicrobial agent having a high antibacterial activity against gram positive and gram negative bacteria in vitro and in vivo [1]. The mechanism of the activity is based on the inhibition of the DNA-gyrase of the bacteria. In vitro studies had shown that OFX has early bactericidal activity against Mycobatcerium tuberculosis [2]. The efficiency of OFX, rifampicin (RMP) and isoniazid (INH) was prospectively compared with the regimen of ethambutol (EMB), RMP and INH for the primary treatment of pulmonary

\footnotetext{
*Corresponding author. Tel.: +91-44-8265-425/27/35/57; fax: +91-44-8262-137.

E-mail address: trcicmr@md3.vsnl.net.in (C. Immanuel).
}

tuberculosis and OFX appears to be as useful as ethambutol [3].

Monitoring of OFX concentrations in body fluids may be valuable to adjust the drug dosage and to study drug-drug interactions when co-administered with other anti-tuberculosis drugs. Several high-performance liquid chromatography (HPLC) methods have been developed for measuring OFX concentration in body fluids, based on the natural fluorescence of the quinolone nucleus. In previously published methods, the extraction procedures used were tedious and the yield was not sufficient [4-7]. A simple and rapid assay procedure using the sample preparation as described in Ref. [8] and the mobile phase as given in Ref. [9] was developed by us. The method involves deproteinisation of the plasma sample, injection of the protein-free supernatant 
directly into the reversed-phase HPLC column and detection using fluorescence emission.

The aim of this study was to develop and validate a simple and rapid HPLC assay for measuring OFX levels in plasma and urine that is free of interference from other anti-tuberculosis drugs. After the validation, the method was evaluated in samples collected from healthy volunteers who were administered OFX alone or in combination with RMP. The results were compared with those of microbiological assay (MBA) currently in use in our laboratory [10].

\section{Experimental}

\subsection{Chemicals}

OFX tablets were obtained from Dee Pharma (India). Pure OFX standard was from Sigma (St. Louis, MO, USA). Acetonitrile, HPLC grade was from Merck (India) and the chemicals disodium hydrogenphosphate and orthophosphoric acid used were of analytical grade. Deionised water was processed through a Milli-Q water purification system (Millipore, USA).

\subsection{Chromatographic system}

The HPLC system consisted of a Crystal 2000 Series HPLC pump (ATI UNICAM, UK) equipped with a PU 4027 fluorescence detector (PyeUnicam, UK). A Rheodyne manual injector with a $100-\mu l$ sample loop (Rheodyne, USA) attached was used for loading the sample. The data collection and integration were done using a PU 6020 data capturing unit and PU 6000 software (PyeUnicam). Quantitation was achieved on the basis of peak height of calibration standards. The analytical column was a YMC pack ODS.A, $250 \times 4.6 \mathrm{~mm}$ I.D., $5 \mu \mathrm{m}$ particle size with matched guard column (YMC, USA).

The mobile phase consisted of $50 \mathrm{~m} M$ phosphate buffer ( $\mathrm{pH} 2.6$ adjusted with $1.5 \mathrm{M}$ disodium hydrogenphosphate)-acetonitrile $(82: 18, \mathrm{v} / \mathrm{v})$. Before the preparation of the mobile phase, the phosphate buffer and acetonitrile were degassed separately using a Millipore vacuum pump. The fluorescence detector was set up at an excitation wavelength of $290 \mathrm{~nm}$ and an emission wavelength of $460 \mathrm{~nm}$ with attenua- tion 8 and gain 10 . The chromatogram was run for $10 \mathrm{~min}$ at a flow-rate of $1.5 \mathrm{ml} / \mathrm{min}$.

\subsection{Preparation of standard solution}

A stock standard $(1 \mathrm{mg} / \mathrm{ml})$ was prepared by dissolving OFX in $0.1 \mathrm{M} \mathrm{HCl}$ initially, and then made up to the volume with Milli-Q water. The working standards of OFX in concentrations ranging from 0.5 to $10.0 \mu \mathrm{g} / \mathrm{ml}$ were prepared in plasma or urine diluted 1:50 with Milli-Q water. The plasma standards were prepared using horse plasma from the King Institute, India.

\subsection{Precision}

The precision of the method was evaluated by analysing pooled human plasma samples containing three different concentrations of OFX. The withinday and between-day variations were determined by assaying each sample in triplicate for 3 days.

\subsection{Recovery}

For the recovery experiment, the same-pooled human plasma samples containing previously determined concentrations of OFX were spiked with 1 , 2 and $4 \mu \mathrm{g} / \mathrm{ml}$ OFX and assayed. The percentage of recovery was calculated by dividing sample differences with the added concentrations.

\subsection{Samples}

Sixty plasma and 24 urine samples were obtained from 12 healthy volunteers admitted in a recent study on pharmacokinetics of OFX and stored at $-20^{\circ} \mathrm{C}$. The plasma samples represented serial samples drawn at 1, 2, 3, 6 and $8 \mathrm{~h}$ following a single oral dose of $15 \mathrm{mg} / \mathrm{kg}$ OFX alone (six subjects) or in combination with $15 \mathrm{mg} / \mathrm{kg}$ of RMP (six subjects). Urine was collected over the period of $0-4$ and 4-8 $\mathrm{h}$ after the administration of the drug. These samples were previously analysed for OFX concentrations by MBA. 


\subsection{Sample preparation}

To $0.5 \mathrm{ml}$ each of the calibration standards and test samples, $0.3 \mathrm{ml}$ of $7 \%$ perchloric acid was added, vortex-mixed for $1 \mathrm{~min}$ and centrifuged at $2500 \mathrm{rpm}$ for $15 \mathrm{~min}$. A $100-\mu \mathrm{l}$ volume of the supernatant was directly injected to the column. Urine samples were suitably diluted (1:50, 1:100 and 1:200) and then treated the same way as plasma.

\section{Results and discussion}

Several HPLC methods have been described to measure OFX levels in plasma and urine for therapeutic monitoring. A survey of these papers revealed, that some of them are quite complex and lengthy because of the extraction step in sample preparation [6,7]. The mobile phase containing ion-pair reagents such as, 1-heptanesulphonic acid and tetrabutylammonium hydrogen sulphate were used [5,8], which could cause problem in column maintenance. In contrast, the present method has the advantages of being simple and rapid. The technique involved simple steps like deprotenisation/dilution and since there was no extraction step, the sample preparation time was shorter $(15 \mathrm{~min})$ and there was no loss of the analyte. The $\mathrm{pH}$ of the mobile phase was 2.6 at which the fluorescence intensity of OFX is maximum [13] and it does not contain any ion-pair reagents. Under these chromatographic conditions, sufficient resolution was obtained with shorter chromatographic run time (10 min).

Fig. 1 shows representative chromatograms of drug-free human plasma, and plasma and urine samples obtained after ingestion of $15 \mathrm{mg} / \mathrm{kg}$ of OFX. The retention time was $7 \mathrm{~min}$. It can be seen from the chromatograms that both in plasma and urine, OFX is separated as a single peak without its metabolites. OFX is metabolised to three metabolites namely, ofloxacin glucuronide, demethyl ofloxacin and ofloxacin- $N$-oxide [11]. In normal individuals less than $5 \%$ of OFX is excreted in the urine as metabolites [12]. Such low metabolite concentrations are of negligible clinical importance and hence no attempt was made to separate them.

The calibration curve data and parameters for OFX are given in Table 1. The concentrations of

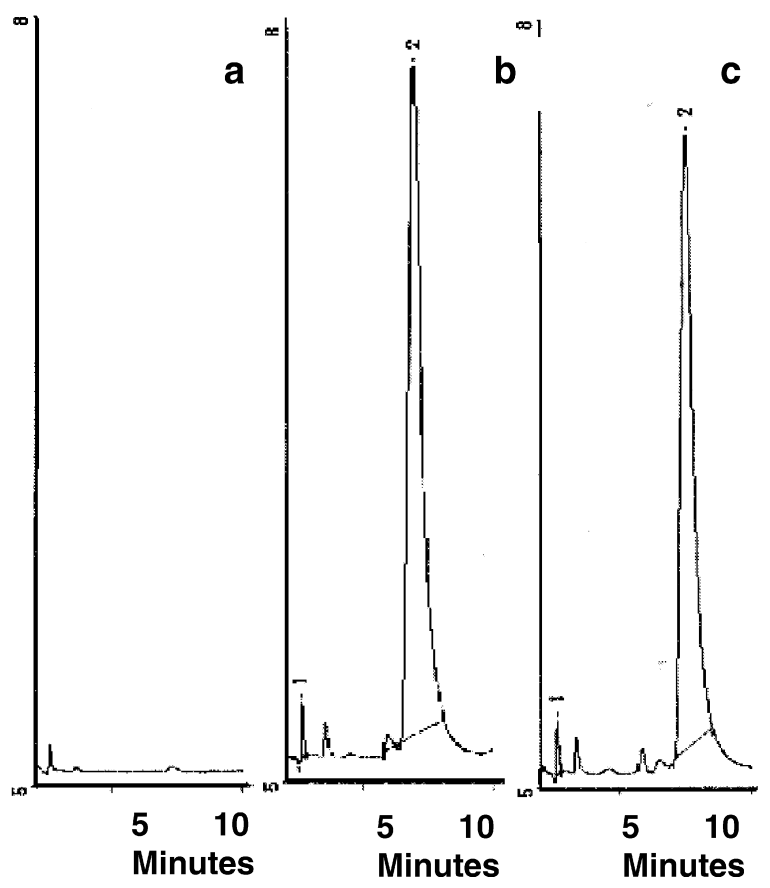

Fig. 1. Chromatograms of drug-free plasma (a), and of (b) OFX in plasma $(4.7 \mu \mathrm{g} / \mathrm{ml})$ and (c) urine $(3.8 \mu \mathrm{g} / \mathrm{ml})$. Peak $2=\mathrm{OFX}$.

standards ranged from 0.5 to $10.0 \mu \mathrm{g} / \mathrm{ml}$. A linear relationship was observed between peak heights and the concentrations over this range with correlation coefficients ranging from 0.9948 to 0.9998 . When a concentration of $0.25 \mu \mathrm{g} / \mathrm{ml}$ was determined, in spite of the change in the response (above the base level) the integrator did not detect the height at this setting (attenuation 8 and gain 10). Under these operating conditions the detection limit was $0.5 \mu \mathrm{g} /$ $\mathrm{ml}$, which in any case was lower than the expected range for pharmacokinetic studies done up to $8 \mathrm{~h}$. However, the calibration curve was constructed with the following concentrations, viz. 1.0, 2.5 and 5.0 $\mu \mathrm{g} / \mathrm{ml}$ for routine assay where therapeutic concentrations can be conveniently interpolated for both plasma and urine samples. The reproducibility of the

Table 1

Calibration curve parameters for OFX in plasma

\begin{tabular}{llll}
\hline Day & Slope & Intercept & $r$-value \\
\hline I & 1.22 & -0.42 & 0.9949 \\
II & 0.97 & -0.30 & 0.9999 \\
III & 0.92 & -0.19 & 0.9998 \\
\hline
\end{tabular}


Table 2

Linearity and reproducibility of the standards

\begin{tabular}{lll}
\hline $\begin{array}{l}\text { Standard concentration } \\
(\mu \mathrm{g} / \mathrm{ml})\end{array}$ & \multicolumn{2}{l}{ Mean peak height \pm SD $(\mathrm{RSD}, \%)$} \\
\cline { 2 - 3 } & Plasma $(n=4)$ & Urine $(n=4)$ \\
\hline 1.0 & $1.35 \pm 0.11(8.1)$ & $1.49 \pm 0.03(2.0)$ \\
2.5 & $3.43 \pm 0.18(5.2)$ & $3.64 \pm 0.34(9.1)$ \\
5.0 & $6.85 \pm 0.48(7.0)$ & $7.57 \pm 0.70(9.4)$ \\
\hline
\end{tabular}

three standards used for constructing calibration graphs for both plasma and urine are given in Table 2. The within-run relative standard deviation (RSD) ranged from 1.3 to $2.6 \%$ and between-run RSD ranged from 2.4 to $3.4 \%$ (Table 3 ). The recovery ranged from 90 to $98 \%$ (Table 4 ).

The method described was applied for the determination of OFX concentrations in plasma and urine from 12 healthy subjects, six of whom were given OFX alone and the rest in combination with RMP. Fig. 2 presents the mean plasma concentrations of OFX at various time intervals. The pharmacokinetic profile is not different for patients who had OFX alone or in combination with RMP. The specificity in relation to other anti-tuberculosis drugs was not a matter of concern since, the assay is based

Table 3

Precision of OFX assay in plasma

\begin{tabular}{lll}
\hline & $\begin{array}{l}\text { Concentration } \\
\text { Mean } \pm \text { SD } \\
(\mu \mathrm{g} / \mathrm{ml})\end{array}$ & $\begin{array}{l}\text { RSD } \\
(\%)\end{array}$ \\
\hline Intra-assay precision & $1.40 \pm 0.04$ & 2.6 \\
& $3.34 \pm 0.05$ & 1.3 \\
& $5.82 \pm 0.10$ & 1.7 \\
Inter-assay precision & $1.40 \pm 0.05$ & 3.4 \\
& $3.28 \pm 0.08$ & 2.4 \\
& $5.82 \pm 0.19$ & 3.2 \\
\hline
\end{tabular}

Table 4

Recovery of OFX in plasma

\begin{tabular}{lll}
\hline $\begin{array}{l}\text { Added } \\
(\mu \mathrm{g} / \mathrm{ml})\end{array}$ & $\begin{array}{l}\text { Found } \\
\text { Mean } \pm \mathrm{SD} \\
(\mu \mathrm{g} / \mathrm{ml})\end{array}$ & $\begin{array}{l}\text { Recovery } \\
(\%)\end{array}$ \\
\hline 0 & $1.26 \pm 0.04$ & \\
1.0 & $2.23 \pm 0.19$ & 98 \\
0 & $3.04 \pm 0.08$ & \\
2.0 & $4.86 \pm 0.28$ & 91 \\
4.0 & $6.62 \pm 0.52$ & 90 \\
\hline
\end{tabular}

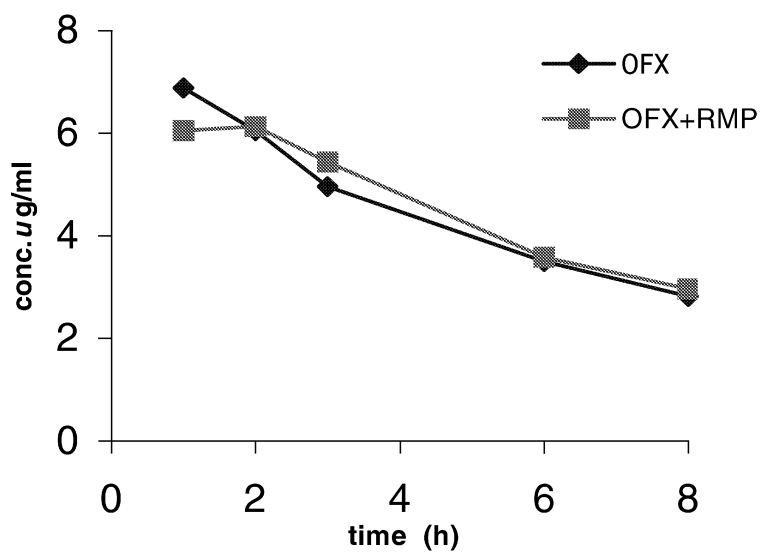

Fig. 2. The mean concentrations of OFX in plasma from healthy volunteers.

on the natural fluorescence of the quinolone nucleus, which the other anti-tuberculosis drugs namely RMP, INH and PZA do not have.

Fig. 3a compares OFX data obtained by HPLC and MBA assays in plasma. A total of 60 samples were compared. The mean plasma concentration of OFX was $4.84 \mu \mathrm{g} / \mathrm{ml}$ by HPLC and $4.58 \mu \mathrm{g} / \mathrm{ml}$ by MBA. This difference was not statistically significant $(p>0.2)$. However the agreement between the two methods was not very high, as the correlation coefficient was only 0.76 .

Fig. $3 \mathrm{~b}$ shows the comparison of concentrations in 24 urine samples by both the methods. The mean concentrations were $236 \mu \mathrm{g} / \mathrm{ml}$ by HPLC and 232 $\mu \mathrm{g} / \mathrm{ml}$ by MBA. The correlation coefficient was 0.99 .

On the basis of the above values measured by both the methods, the summary measures of OFX namely, area under concentration curve (AUC 0-8 h) and proportion $(\%)$ of dose excreted over the $0-8 \mathrm{~h}$ period were calculated. The mean values of AUC were 30.7 and $28.1 \mu \mathrm{g} / \mathrm{ml}$.h for HPLC and MBA, respectively. The proportions (\%) of dose excreted were 39.4 and $37.6 \%$ for HPLC and MBA, respectively. Neither of the differences was statistically significant $(p>0.2)$, suggesting either method may be useful for pharmacokinetics studies.

In conclusion, the HPLC method described here for the determination of OFX in plasma and urine is simple, sensitive and precise with an accuracy of greater than $90 \%$. The assay is less laborious and 


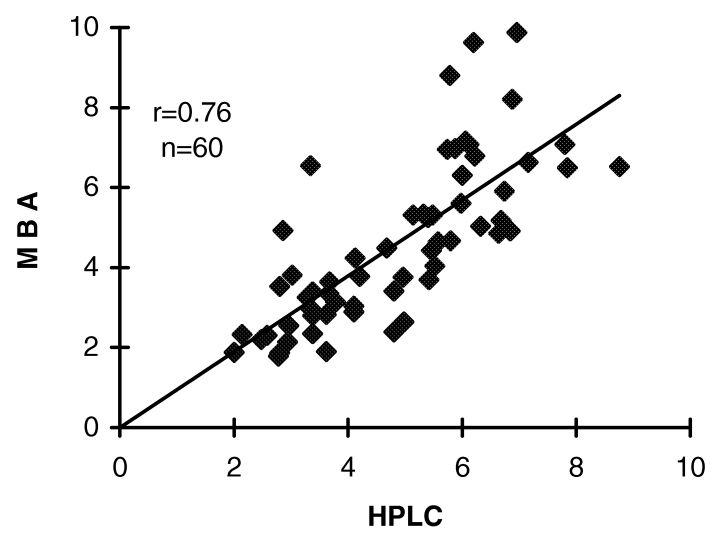

(a)

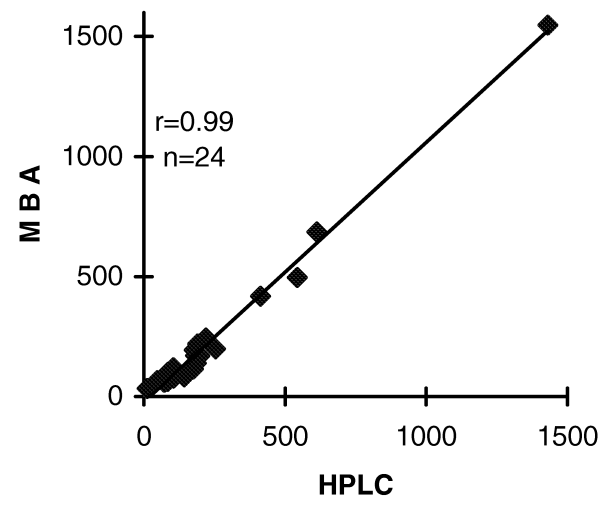

(b)

Fig. 3. (a) Plasma concentrations of OFX $(\mu \mathrm{g} / \mathrm{ml})$ by two methods. (b) Urinary concentrations of OFX ( $\mu \mathrm{g} / \mathrm{ml})$ by two methods.

time consuming than the bioassay, permitting the process of more samples and therefore more suitable for kinetic studies.

\section{Acknowledgements}

The authors wish to thank Sara Mathew for her valuable suggestions in preparing the manuscript and Dr. K. Jayasankar for his technical advice. The authors acknowledge the support provided by Dr. P.R. Narayanan, Director and Dr. Prema Gurumurthy, Deputy Director, TRC, Chennai.

\section{References}

[1] K. Sato, Y. Matsura, M. Inoue, T. Ueno, Y. Osada, H. Ogawa, M. Mitsuhashi, Antimicrob. Agents Chemother. 22 (1982) 548.

[2] D. Herbert, C.N. Paramasivan, P. Venkatesan, G. Kubendiran,
R. Prabhakar, D.A. Mitchison, Antimicrob. Agents Chemother. 40 (1996) 2296.

[3] S. Kohno, H. Koga, M. Kaku, S. Maesaki, K. Hara, Chest 102 (1992) 1815.

[4] A. Le Coguie, R. Bidault, R. Frarinotti, A. Dauphin, J. Chromatogr. 434 (1988) 320.

[5] A. Mignot, M.A. Lefebvre, J. Chromatogr. 430 (1988) 192.

[6] Y. Katagiri, K. Naora, N. Ichikawa, M. Hayashibara, K. Iwamoto, J. Chromatogr. 431 (1988) 135.

[7] K.H. Lehr, P. Damm, J. Chromatogr. 425 (1988) 153.

[8] D.J. Griggs, R. Wise, J. Antimicrob. Chemother. 24 (1989) 437.

[9] K. Kosuge, T. Uematsu, S. Araki, H. Matsuno, K. Ohashi, M. Nakashima, Antimicrob. Agents Chemother. 42 (1998) 1298.

[10] P. Gurumurthy, G. Ramachandran, A.K. Hemanth Kumar, P. Venkatesan, V. Chandrasekar, P.R. Narayanan, Ind. J. Pharmacol. 30 (1998) 263.

[11] K. Borner, H. Lode, Infection 14 (1986) 554.

[12] H. Lode, G. Hoffken, P. Olschewski, B. Sievers, A. Kirch, K. Barner, P. Koeppe, Antimicrob. Agents Chemother. 31 (1987) 1338.

[13] J.S. Chapman, N.H. Georgopapadakou, Antimicrob. Agents Chemother. 33 (1989) 27. 